Article publié par le Laboratoire de Construction en Béton de l'EPFL

Paper published by the Structural Concrete Laboratory of EPFL

\begin{tabular}{|l|l|}
\hline Title: & Punching shear strength of steel fibre reinforced concrete slabs \\
\hline Authors: & Maya Duque L. F., Fernández Ruiz M., Muttoni A., Foster S. J. \\
\hline Published in: & Engineering Structures \\
\hline $\begin{array}{l}\text { Volume: } \\
\text { Pages: }\end{array}$ & $\begin{array}{l}\text { Vol. 40 } \\
\text { pp. 93-94 }\end{array}$ \\
\hline Country: & UK \\
\hline Year of publication: & 2012 \\
\hline Type of publication: & Peer reviewed journal article \\
\hline
\end{tabular}

Please quote as:

Maya Duque L. F., Fernández Ruiz M., Muttoni A., Foster S. J., Punching shear strength of steel fibre reinforced concrete slabs, Engineering Structures, Vol. 40, UK, 2012, pp. 93-94. 


\title{
Punching shear strength of steel fibre reinforced concrete slabs
}

\author{
L.F. Maya ${ }^{\mathrm{a}, *}$, M. Fernández Ruiz ${ }^{\mathrm{a}}$, A. Muttoni ${ }^{\mathrm{a}}$, S.J. Foster ${ }^{\mathrm{b}}$ \\ ${ }^{a}$ Ecole Polytechnique Fédérale de Lausanne, Station 18, CH-1015 Lausanne, Switzerland \\ ${ }^{\mathrm{b}}$ School of Civil and Environmental Engineering, The University of New South Wales (UNSW), 2052 Sydney, Australia
}

\section{A R T I C L E I N F O}

\section{Article history:}

Received 3 November 2011

Revised 24 January 2012

Accepted 5 February 2012

\section{Keywords:}

Punching

Fibre reinforced concrete

Critical shear crack theory

Variable Engagement Model

Design models

\begin{abstract}
A B S T R A C T
The ultimate strength of reinforced concrete slabs is frequently governed by the punching shear capacity, which may be increased with addition of traditional fitments such as reinforcing steel, headed studs or shear heads. In addition to these traditional methods of strengthening against punching, steel fibre reinforcement has proved to be an effective and viable alternative. The addition of fibres into the concrete improves not only the shear behaviour but also the deformation capacity of reinforced concrete slabs. This paper presents a mechanical model for predicting the punching strength and behaviour of concrete slabs reinforced with steel fibres as well as conventional reinforcement. The proposed model is validated against a wide number of available experimental data and its accuracy is verified. On this basis, a simple design equation for the punching shear capacity of steel fibre reinforced concrete (SFRC) slabs is proposed.
\end{abstract}

Crown Copyright $\odot 2012$ Published by Elsevier Ltd. All rights reserved.

\section{Introduction}

Given their construction and architectural advantages, reinforced concrete flat slabs are commonly used in medium height office buildings, residential buildings and parking stations. The flat soffit makes the formwork and reinforcement substantially simpler, allowing for easy placement and installation and offers lower overall storey heights. The ultimate strength of a reinforced concrete flat slab is usually governed by the punching shear capacity at its slabcolumn connections. This failure mode is typically brittle and can lead to progressive collapses and loss of the entire structure [14]. A number of alternatives are available for increasing the punching shear capacity, such as the use of closed stirrups, bent-up bars, shear studs or post-installed shear reinforcement. More recently, the use of fibre reinforced concrete (FRC) for increasing the punching shear capacity has been studied (e.g. [5-10]). These studies have confirmed an increase in the punching shear strength of FRC slabs as well as an increase in their deformational capacity and this enhancement is mostly due to the bridging action of the fibres after the cracking of the concrete matrix (shown in Fig. 1).

Current code provisions for slab-column connections, such as, for example, ACI 318-11 [11], JSCE [12], and the fib Model Code 2010 [13,14], have been developed for normal concrete structures and their application to FRC slab-column connections is not always straightforward, particularly for empirical design formulae. To this end, several specific models for punching shear of FRC

\footnotetext{
* Corresponding author.

E-mail addresses: femayadu@gmail.com (L.F. Maya), miguel.fernandezruiz@ epfl.ch (M. Fernández Ruiz), aurelio.muttoni@epfl.ch (A. Muttoni), s.foster@unsw. edu.au (S.J. Foster).
}

slab-column connections have been proposed over the last decades. Narayanan and Darwish [6] provided a design equation for the punching shear capacity of SFRC slab considering the strength of the compressive zone above the top of the inclined cracks, the pull-out shear forces on the fibres along the inclined cracks and the shear forces carried by dowel and membrane actions. Harajli et al. [8] proposed an empirical design equation for the punching shear capacity of SFRC slab-column connections based on a best fit linear regression of the coupled contribution of concrete and fibres. Choi et al. [15] performed a theoretical study to propose a design equation based on a FRC failure criteria. The formula proposed considers the assumption that yielding of tensile reinforcement occurs prior to punching shear failures, which is valid for thin slabs with large span to thickness ratios. The contributions of compressive and tensile zones at the critical section were taken into account and the punching shear capacity of both zones was assumed to be controlled by tensile cracking, rather than compressive crushing. More recently, Higashiyama et al. [16] proposed a design equation based on the JSCE model for assessing the punching shear capacity of normal concrete slab-column connections. The equation takes into account the fibre pull-out strength to estimate the contribution of the fibres and considers the perimeter of the critical section depending on the quantity of fibres and their properties.

\section{Punching shear strength based on the critical shear crack theory}

\subsection{Critical shear crack theory}

The ultimate punching shear strength and deformation capacity of reinforced concrete slabs can be estimated using the mechanical 


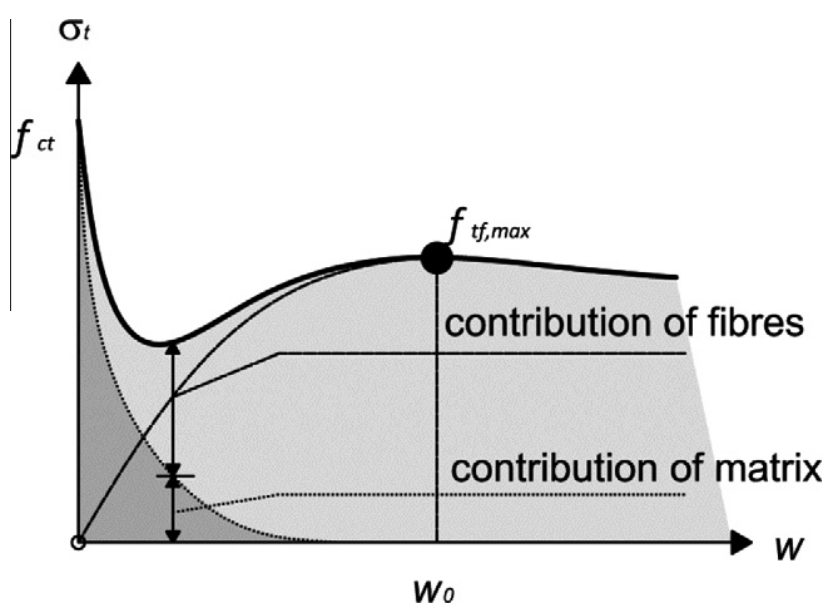

Fig. 1. Post-cracking behaviour of fibre-reinforced concrete. Matrix and fibre contributions.

model of the critical shear crack theory (CSCT), as has been presented by Muttoni [17] for slabs without transverse reinforcement and Fernández Ruiz and Muttoni [18] for slabs with transverse reinforcement. According to the CSCT, the opening of a critical shear crack reduces the strength of the inclined concrete compressive strut carrying shear and eventually leads to the punching shear failure. Thus, as the opening of the critical shear crack increases with slab rotations, the punching shear strength decreases. According to Muttoni and Schwartz [19], the width of the critical shear crack $(w)$ can be assumed to be proportional to the slab rotation $(\psi)$ multiplied by the effective depth of the member $(d)$; that is, $w \propto \psi d$ as illustrated in Fig. 2.

A failure criterion for the punching shear strength of reinforced concrete slabs without transverse reinforcement was proposed by Muttoni [17] as

$\frac{V_{R, c}}{b_{0} d \sqrt{f_{c}}}=\frac{3 / 4}{1+15 \frac{\psi d}{d_{g 0}+d_{g}}}$

where $\psi$ is the maximal rotation of the slab; $d$ is the effective depth of the slab; $b_{0}$ is the control perimeter at a distance of $d / 2$ from the face of the column; $f_{c}$ is the compressive strength of concrete; $d_{g}$ is the aggregate size, and $d_{\mathrm{g} 0}$ is a reference aggregate size set to $16 \mathrm{~mm}$. The failure criterion of Eq. (1) takes into account the influence of the concrete strength and the crack roughness by considering the maximum aggregate size $d_{g}$.

To determine the ultimate punching shear strength and the deformational capacity, the load-rotation relationship of the slab

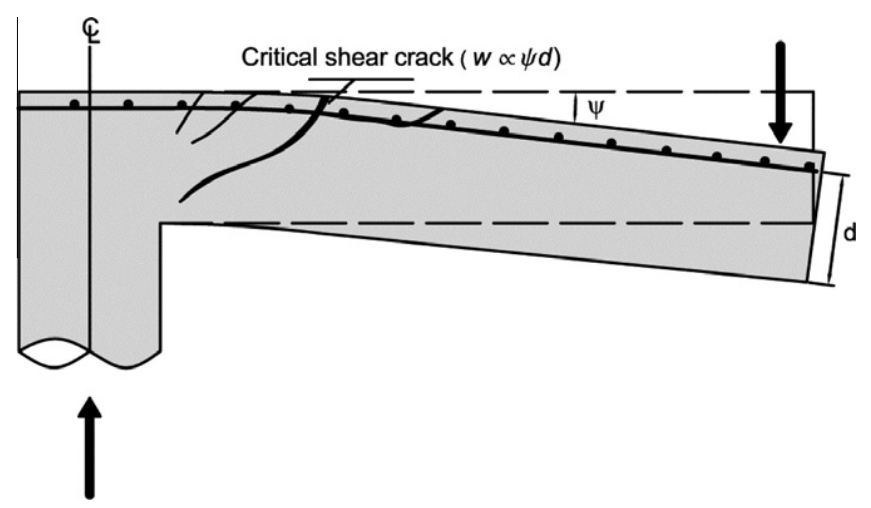

Fig. 2. Critical shear crack developing through the theoretical compression strut.

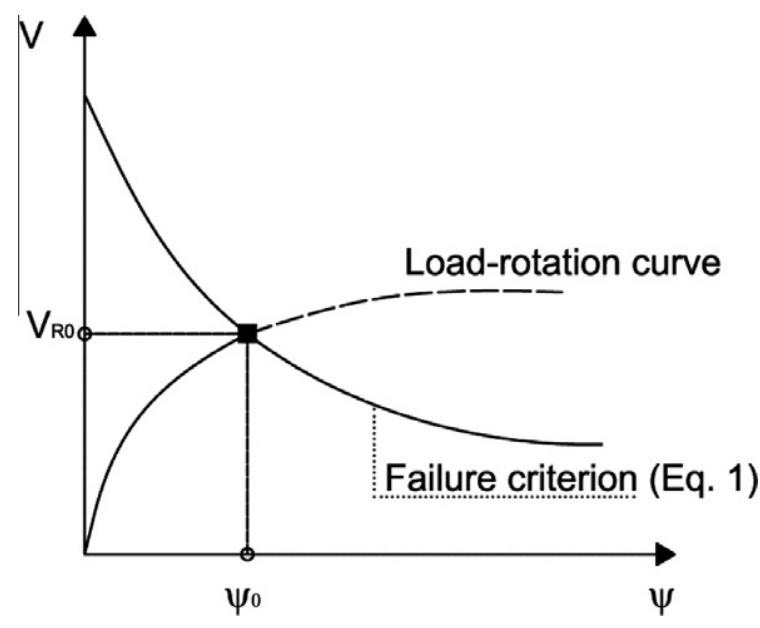

Fig. 3. Assessment of punching shear strength and deformation capacity according to the CSCT.

must be known. As shown in Fig. 3, the intersection between the estimated load-rotation relationship and the failure criterion defined by Eq. (1) corresponds to the predicted ultimate failure load and rotation. For complex cases, this relationship can be obtained by carrying out a non-linear numerical simulation of the flexural behaviour of the slab, for instance using non-linear finite-element analysis (NLFEA). The load-rotation for axisymmetric cases can also be obtained analytically after some simplifications considering a quadrilinear or bilinear moment-curvature relationship for the reinforced concrete cross-section [17]. This approach allows taking into account the contribution of the fibres to the flexural strength in a simple manner. To that aim, an effective tensile strength of the FRC at the cross-section can be adopted to calculate the quadrilinear moment-curvature relationship, as illustrated in Fig. 4.

The expressions for the quadrilinear moment curvature relationship presented in Fig. 4a can be calculated assuming the material behaviours for the concrete and for the steel presented in Fig. $4 \mathrm{c}$ and e. Prior to yielding of the flexural reinforcement, the actual stress distribution over the cross section in Fig. 4b is idealized through a linear stress-strain relationship for the concrete in the compressive zone and an average strength is assumed for the FRC in the tensile zone, Fig. 4c. To calculate the ultimate flexural capacity, the actual stress distribution in Fig. $4 \mathrm{c}$ is idealized assuming an equivalent rectangular compressive stress block and an average tensile strength of FRC, Fig. 4e. Following a similar procedure as that described in Muttoni [17] and included in Appendix C, the following expressions are obtained:

$E I_{0}=\frac{E_{c} h^{3}}{12}$

$E I_{1}=\rho \beta E_{s} d^{3}\left(1-\frac{c}{d}\right)\left(1-\frac{c}{3 d}\right)$

$c=\rho \beta \frac{E_{s}}{E_{c}} d\left(\sqrt{1+\frac{2 E_{c}}{\rho \beta E_{s}}}-1\right)$

$m_{c r}=\frac{f_{c t} h^{2}}{6}$

$\begin{aligned} m_{R}= & \rho d^{2} f_{y}\left[1-\frac{\beta_{1}\left(\rho f_{y}+f_{c t 2 . f} h / d\right)}{2\left(\alpha_{c c} f_{c}+f_{c t 2 . f}\right)}\right] \\ & +\frac{h^{2} f_{c t 2 . f}}{2}\left[1-\frac{\rho f_{y} d / h+f_{c t 2 . f}}{\left(\alpha_{c c} f_{c}+f_{c t 2 . f}\right)}\right]\left[1+\frac{\rho f_{y} d / h+f_{c t 2 . f}}{\left(\alpha_{c c} f_{c}+f_{c t 2 . f}\right)}\left(1-\beta_{1}\right)\right]\end{aligned}$ 
where $\beta$ is an efficiency factor that accounts for the orthogonal layout of the reinforcement and the reduction in the ratio between torsional and flexural stiffness of the slab after cracking, with a value $\beta=0.6$ proposed by Mutonni [17]; $E I_{0}$ and $E I_{1}$ refer to the uncracked and cracked bending stiffness respectively; $E_{s}$ and $E_{c}$ are the young modulus of steel and concrete respectively; $f_{c t}$ is the tensile strength of the FCR, $m_{c r}$ is the cracking moment per unit of width; and $m_{R}$ is the nominal moment capacity per unit of width. The parameter $\beta_{1}=x_{p l} / c$ defines the depth of the equivalent rectangular stress block (Fig. 4c). Some approaches account for a constant value of the parameter $\beta_{1}$ (for instance, $\beta_{1}=0.85$ [20]). Other approaches propose this parameter as a function of $f_{c}$, for instance $\beta_{1}=0.80-\left(f_{c k}-50\right) / 400$ as proposed in the draft of Model Code 2010 [13,14], which is the formulation adopted hereafter. Likewise, the factor $\alpha_{c c}$ that accounts for long term effects on the compressive strength and unfavourable effects due to the load conditions is adopted as proposed in the draft of Model Code 2010 [13,14]. The characteristic curvatures of the moment-curvature diagram can thus be calculated as

$$
\begin{aligned}
& -\chi_{c r}=\frac{m_{c r}}{E I_{0}}=\frac{2 f_{c t}}{h E_{c}} \\
& \chi_{T S}=\frac{f_{c t}}{6 \rho \beta h E_{s}} \\
& -\chi_{1}=\frac{m_{c r}}{E I_{1}}-\chi_{T S} \\
& -\chi_{y}=\frac{m_{R}}{E I_{1}}-\chi_{T S}
\end{aligned}
$$

For the axisymmetric slab presented in Fig. 5, its load versus local-deflection response can be calculated analytically after some simplifications. The tangential cracks and the radial curvature are concentrated in the vicinity of the column. Outside the critical shear crack located at a radius $r_{0}$, the radial moment and the radial curvature decrease rapidly. Therefore, it is assumed that the corresponding slab portion deforms following a conical shape with a constant slab rotation $\psi$, as shown in Fig. 5a. The equilibrium of forces is performed along the cross sections defined by the inclined cracks in Figs. 5b and $\mathrm{c}$ and it is expressed through Eq. (4) [17].

$V \frac{\Delta \varphi}{2 \pi}\left(r_{q}-r_{c}\right)=-m_{r} \Delta \varphi r_{0}-\Delta \varphi \int_{r_{0}}^{r_{s}} m_{\varphi} d r$

$\chi_{t}=-\frac{\psi}{r} \quad$ for $r>r_{0}$

$\chi_{r}=\chi_{t}=-\frac{\psi}{r_{0}} \quad$ for $r \leqslant r_{0}$

The expression for the load-rotation relationship can be calculated by assessing the radial moment acting in the slab at a distance of $r_{0}$ from the centerline of the column and integrating the moment distribution in the tangential direction considering the quadrilinear moment-curvature relationship given in Fig. 4. This is discussed in detail in Mutonni [17], with the resulting load-rotation relationship given by

$$
\begin{aligned}
V= & \frac{2 \pi}{r_{q}-r_{c}}\left\{-m_{r} r_{0}+m_{R}\left\langle r_{y}-r_{0}\right\rangle+E I_{1} \psi\left\langle\ln \left(\frac{r_{1}}{r_{y}}\right)\right\rangle+E I_{1} \chi_{T S}\left\langle r_{1}-r_{y}\right\rangle\right. \\
& \left.+m_{c r}\left\langle r_{c r}-r_{1}\right\rangle+E I_{0} \psi\left\langle\ln \left(\frac{r_{s}}{r_{c r}}\right)\right\rangle\right\}
\end{aligned}
$$

where the operator $\langle x\rangle$ is $x$ for $x>0$ and 0 for $x \leqslant 0$ and $m_{r}$ is the radial moment per unit of length acting on a transversal cross section at a distance of $r_{0}=r_{c}+d$ (neglecting moment shift due to the vertical component of fibre stresses and calculated adopting the simplified average stress distribution illustrated in Figs. 4c and e, where the crack opening $w_{1}$ and $w_{2}$ were assumed as $1.0 \mathrm{~mm}$ and $3.0 \mathrm{~mm}$ respectively). Definition of other parameters can be consulted in Appendix D of this paper. By applying a number of simpli- fying assumptions, Muttoni [17] showed that Eq. (4) is approximated well by the expression

$V=V_{\text {flex }}\left(\frac{\psi}{1.5 \frac{r_{s} f_{y}}{d E_{s}}}\right)^{2 / 3}$

where $r_{s}$ is the distance from the column axis to the line of contraflexure of the bending moments; $f_{y}$ is the yield strength of the flexural reinforcement; and $E_{s}$ is the modulus of elasticity of the reinforcing steel. From Eq. (5), the flexural strength $\left(V_{\text {flex }}\right)$ can be estimated for the case of a plastic regime as

$V_{\text {flex }}=2 \pi m_{R} \frac{r_{s}}{r_{q}-r_{c}}$

where $m_{R}$ refers to the nominal moment capacity (bending strength) per unit width.

\subsection{Punching shear strength of FRC slabs}

As the CSCT model, described above, is based on the application of a physical-mechanical modelling approach, the punching shear behaviour of FRC slabs can be easily incorporated in a physically consistent manner. Along the failure surface defined by the critical shear crack, shear is carried by the coupled action of the concrete and the fibres, as proposed by Muttoni and Fernández Ruiz [21]. Therefore, the punching shear strength can be calculated as the sum of both contributions as

$V_{R}=V_{R, c}+V_{R, f}$

where $V_{R, c}$ and $V_{R, f}$ are the contributions of the concrete and fibres, respectively, at the point where the angle of rotation $\psi_{R}$ corresponds to the ultimate condition (refer Fig. 6).

As observed in Fig. 6, the contribution of the concrete and fibres are both functions of the critical shear crack, which is assumed to be proportional to the slab rotation angle and the effective depth. The crack opening for a segment of the failure surface at a distance $\xi$ from the soffit of the slab can be estimated using the kinematic assumption of the CSCT [18], as illustrated in Fig. 7a and given by $w(\psi, \xi)=\kappa \psi \xi$

where $w$ is the opening of the critical shear crack and $\kappa$ is a coefficient relating total rotation and critical crack width opening. A value of $\kappa=0.5$ for the coefficient of proportionality is adopted hereafter, as proposed for normal reinforced concrete slabs with transverse reinforcement by Fernández Ruiz and Muttoni [18]. According to this reference, this value provides good agreement to test results in terms of strength and deformational capacity of slabs with the kinematics assumed in Fig. 7a (where the height of the compression chord is neglected). On the basis of Eq. (9), the contribution of fibres can be calculated by integrating the fibre bridging stress corresponding to each crack width across the critical failure surface assumed at an angle of $45^{\circ}$ with the soffit of the slab. Therefore, the fibre contribution is expressed as a function of the slab rotation and the position of the fibres in the slab as illustrated in Fig. 7b

$V_{R . f}=\int_{A_{p}} \sigma_{t f}(w(\xi)) d A_{p}=\int_{A_{p}} \sigma_{t f}(\psi, \xi) d A_{p}$

where $A_{p}$ is the horizontally projected area of the punching shear failure surface, as shown in Fig. 7b.

\subsection{Crack opening-fibre bridging stress relationship}

A suitable crack opening-fibre bridging stress relationship needs to be defined according to Eq. (10). Some simplified relationships based on material testing are proposed in the first complete 


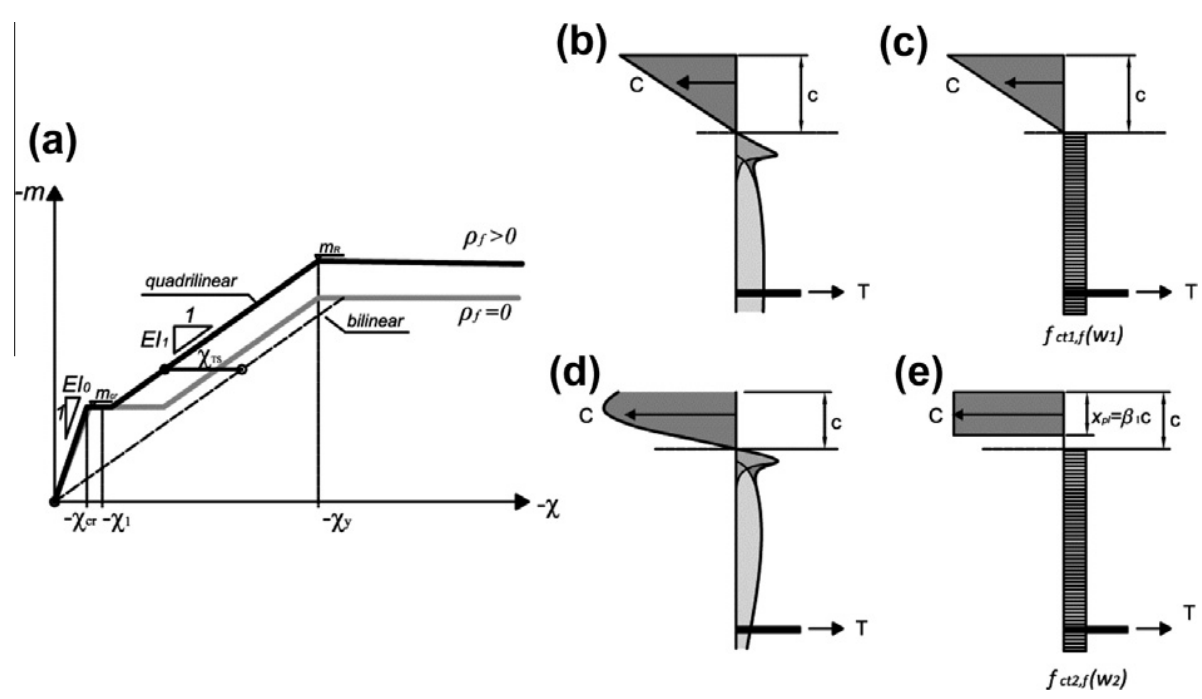

Fig. 4. Quadrilinear moment-curvature relationship: (a) moment-curvature diagram; (b) actual stress distribution over the cross section prior to flexural yielding; (c) adopted material laws prior to flexural yielding; (d) actual stress distribution over the cross section at ultimate flexural strength; and (e) adopted material laws for calculation of flexural strength.

(a)

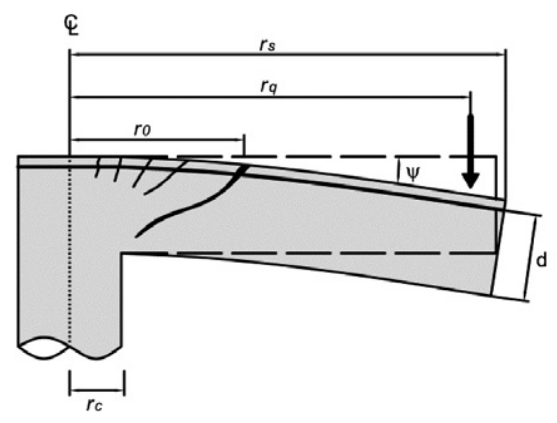

(b)

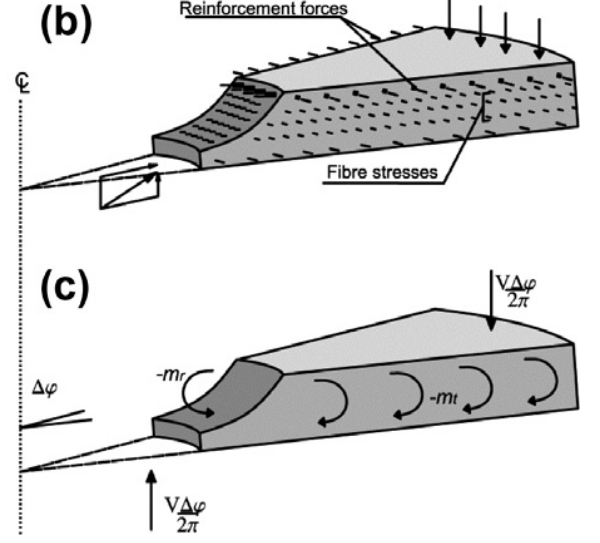

Fig. 5. Axisymmetric slab: (a) geometrical parameters; (b) forces in concrete and reinforcement acting on the slab portion; (c) internal forces acting on the slab portion.

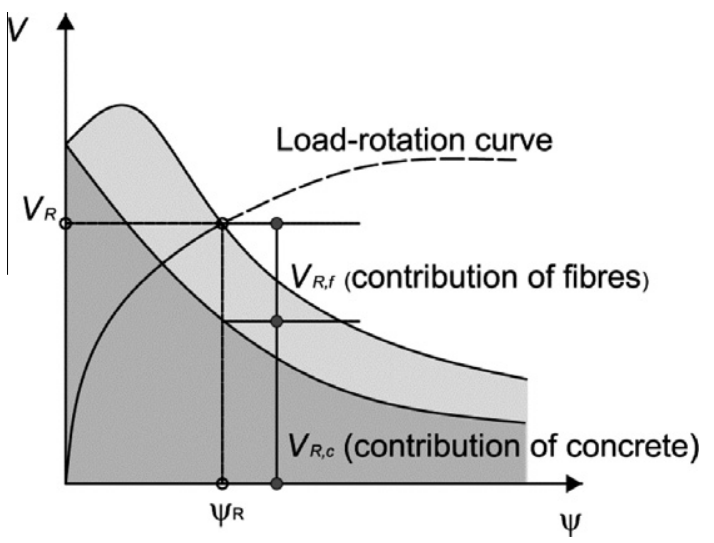

Fig. 6. Coupling of matrix and fibres contributions to punching shear capacity.

draft of Model Code [13,14] for conventional FRC. A number of sophisticated and more accurate models based on deterministic and micromechanical models are also available in the scientific literature, such as those of Aveston and Kelly [22], Lim et al. [23], Li et al. [24] and Voo and Foster [25]. In particular, the Variable
Engagement Model (VEM) proposed by Voo and Foster describes the behaviour of randomly oriented steel fibre reinforced composites subjected to uniaxial tension. According to this model, the tensile strength provided by the fibres over a plane of unit area is given by

$\sigma_{t f}=K_{f} \alpha_{f} \rho_{f} \tau_{b}$

where $K_{f}$ is the global orientation factor; $\rho_{f}$ is the fibre volume; $\tau_{b}$ is the bond stress between the fibres and the concrete matrix; and $\alpha_{f}$ is the aspect ratio of the fibres and is defined as the ratio between the length $\left(l_{f}\right)$ and diameter $\left(d_{f}\right)$ of the fibre $\left(\alpha_{f}=l_{f} / d_{f}\right)$. The orientation factor $K_{f}$ is a function of the crack opening $w$ and can be determined through probabilistic analysis. For the case of randomly oriented fibres where all fibres are pulled out from the matrix and there is no fibre fracture, Voo and Foster defined the global orientation factor as

$K_{f}=\frac{1}{\pi} \arctan \left(\alpha_{e} \frac{w}{d_{f}}\right)\left(1-\frac{2 w}{l_{f}}\right)^{2}$

where $\alpha_{e}$ is an engagement parameter that can be taken for usual cases as $\alpha_{e}=3.5$. The parameter was calibrated using a uniform bond approach along the fibre length and verified against a wide range of experimental data by Voo and Foster $[25,26]$. The interfa- 

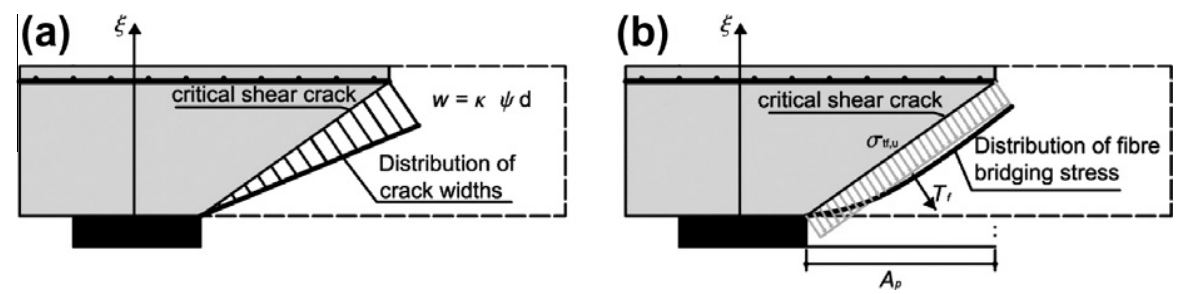

Fig. 7. (a) Assumed distribution of crack widths along the failure surface and (b) fibre bridging stress along the failure surface.

Table 1

Test data and strength predictions.

\begin{tabular}{|c|c|c|c|c|c|c|c|}
\hline \multirow[t]{3}{*}{ References } & \multirow{3}{*}{$\begin{array}{l}\text { Model } \\
\text { Load-rotation } \\
\text { Elements tested }\end{array}$} & \multirow{2}{*}{\multicolumn{2}{|c|}{$\begin{array}{l}\text { CSCT- } V_{R f, I n}(\text { Eq. (14)) } \\
\text { Quadrilinear } \\
V_{\text {Rtest }} / V_{\text {Rcalc }} \\
\end{array}$}} & \multicolumn{4}{|c|}{ CSCT- $V_{R f, \text { simplied }}$ (Eq. (16)) } \\
\hline & & & & \multicolumn{2}{|c|}{$\begin{array}{l}\text { Quadrilinear } \\
V_{\text {Rtest }} / V_{\text {Rcalc }}\end{array}$} & \multicolumn{2}{|c|}{$\begin{array}{l}\text { Simplified(Eq. (6)) } \\
V_{\text {Rtest }} / V_{\text {Rcalc }}\end{array}$} \\
\hline & & Mean & $\mathrm{COV}$ & Mean & $\mathrm{COV}$ & Mean & $\mathrm{COV}$ \\
\hline Cheng and Parra-Motesinos [10] & 10 & 1.09 & 0.08 & 1.10 & 0.08 & 1.13 & 0.08 \\
\hline Theodorakopoulos and Swamy [28] & 20 & 1.08 & 0.06 & 1.09 & 0.07 & 1.14 & 0.07 \\
\hline Alexander and Simmonds [7] & 6 & 1.09 & 0.11 & 1.09 & 0.11 & 1.09 & 0.11 \\
\hline De Hanai and Holanda [29] & 9 & 1.02 & 0.08 & 1.07 & 0.06 & 1.11 & 0.06 \\
\hline Swamy and Ali [5] & 15 & 1.11 & 0.06 & 1.11 & 0.06 & 1.18 & 0.09 \\
\hline McHarg et al. [9] & 4 & 1.08 & 0.05 & 1.08 & 0.05 & 1.17 & 0.07 \\
\hline Suter and Moreillon [30] & 11 & 1.11 & 0.07 & 1.11 & 0.07 & 1.16 & 0.07 \\
\hline Nguyen-Minh et al. [31] & 12 & 1.11 & 0.06 & 1.12 & 0.05 & 1.16 & 0.06 \\
\hline Harajli et al. [8] & 10 & 0.96 & 0.07 & 1.00 & 0.06 & 1.02 & 0.06 \\
\hline Yaseen [32] & 14 & 1.11 & 0.08 & 1.13 & 0.08 & 1.18 & 0.07 \\
\hline Narayanan and Darwish [6] & 12 & 0.98 & 0.07 & 1.02 & 0.06 & 1.05 & 0.06 \\
\hline Higashiyama et al. [16] & 12 & 1.10 & 0.12 & 1.10 & 0.12 & 1.09 & 0.12 \\
\hline Wang et al. [33] & & 5 & 1.14 & 0.06 & 1.15 & 0.07 & 1.21 \\
\hline All elements & 140 & 1.08 & 0.09 & 1.09 & 0.08 & 1.13 & 0.09 \\
\hline
\end{tabular}

cial bond strength between the matrix and the fibre $\tau_{b}$ is defined as a function of the concrete compressive strength and given by

$\tau_{b}=k_{b} \sqrt{f_{c}}$

The bond factor $k_{b}$ is determined by the fibre and matrix type. In the absence of single fibre pullout test data, it may be taken as 0.8 for end-hooked steel fibres, 0.6 for crimped steel fibres, and 0.4 for straight steel fibres [27]. Therefore, the total punching shear contribution of fibres can be derived from Eqs. (9)-(13) and is

$$
\begin{aligned}
V_{R, f} & =\int_{A_{p}} \sigma_{t f}(\psi, \xi) d A_{p} \\
& =\int_{\theta=0}^{2 \pi} \int_{\xi=0}^{d}\left(\frac{1}{\pi} \arctan \left(\alpha_{e} \frac{\kappa \psi \xi}{d_{f}}\right)\left(1-\frac{2 \kappa \psi \xi}{l_{f}}\right)^{2} \alpha_{f} \rho_{f} \tau_{b}\right)\left(r_{c}+\xi\right) d \theta d \xi
\end{aligned}
$$

where $\theta$ is the angle with reference to the axis of the support region. Eq. (14) can be integrated leading to a close-form solution that allows one to calculate the fibre contribution, as derived in Muttoni and Fernández Ruiz [21]. However, this general approach is typically not necessary for most practical applications. For typical FRC concrete slabs, crack widths remain below the crack opening at which the maximal fibre bridging stress is reached. In fact, for fibre dosages typical in slabs and beams, the fibre bridging stresses are fairly constant at the failure surface as is illustrated in Fig. 7b. Therefore, an average fibre bridging stress can be adopted. In so doing, the fibre contribution can be calculated by multiplying this average bridging stress times the area of the failure surface, and thus

$V_{R . f}=\int_{A_{p}} \sigma_{t f}(\psi, \xi) d A_{p}=A_{p} \sigma_{t f}\left(\psi, h_{c}\right)$

where $h_{c}$ is the control distance from the soffit of the slab and $A_{p}$ is the horizontally projected area of the punching shear failure surface.
As proposed by Muttoni and Fernández Ruiz [21], the average bridging stress can be estimated considering the crack opening at a control distance $d / 3$ from the soffit of the slab, which is function of the slab rotation, according to the kinematic assumption adopted in the CSCT. That is

$V_{R, f}=A_{p} \sigma_{t f}\left(w=\frac{\psi d}{6}\right)$

\section{Model validation}

Experimental data available in the literature was used for verification of the proposed mechanical model and consisted of 140 SFRC slab-column connections tested in 13 different studies. The results of the validation are presented in Table 1 and the dimensions and properties of the specimens are summarized in Appendix A. Likewise, the values of the ratio between the measured punching shear strength and the estimated punching shear strength are included in Appendix A.

The best level of approximation is achieved by considering Eq. (1) for concrete (matrix) contribution, the direct integration of Eq. (14) for the fibre contribution, and the quadrilinear momentcurvature curve for the load-rotation relationship. The average ratio between measured-to-predicted punching shear strength following this strategy is 1.08 with a coefficient of variation of 0.09 , as shown in Fig. 8a.

Instead of using the general integration of the fibre bridging stresses, the contribution of fibres can be assessed through Eq. (16) (average fibre bridging stress). In so doing, the average ratio between measured-to-predicted punching shear strength is 1.09 with a coefficient of variation of 0.08 , thus leading to very similar results (Fig. 8b).

In simplifying the model further to the load-rotation relationship defined by Eq. (6), the required calculations are reduced considerably and the method is more suitable for that of typical 
(a) CSCT-V $V_{\text {Rf }}$ Integral (Eq.14)

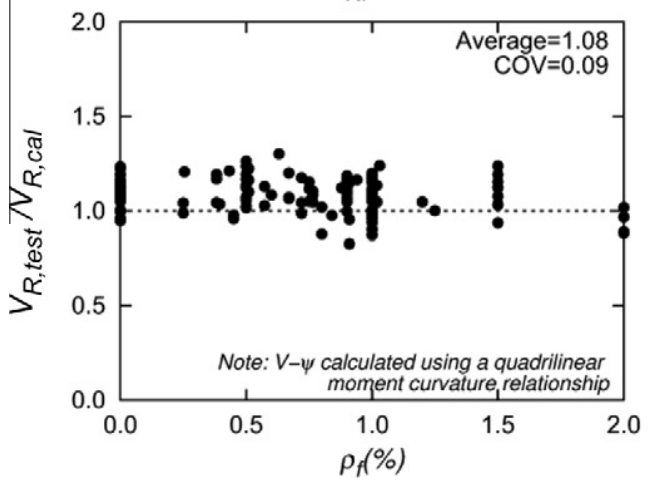

(b) $\operatorname{CSCT}-V_{R f} \operatorname{Simplified(Eq.16)}$

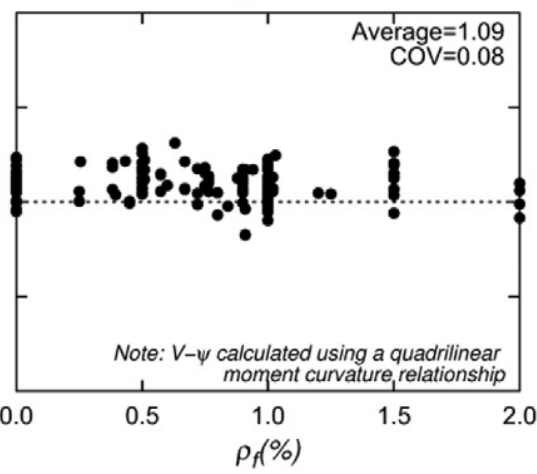

(c) $\operatorname{CSCT}-V_{R f} \operatorname{Simplified(Eq.16)}$

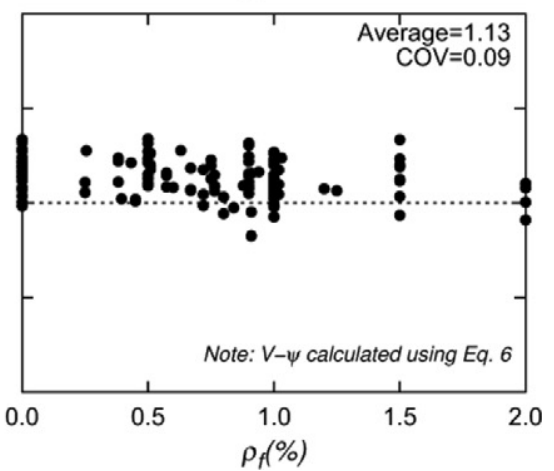

Fig. 8. Punching shear strength predictions for SFRC slabs: (a) CSTC for concrete contribution, VEM integration (Eq. (14)) for fibres contribution and quadrilinear loadrotation relationship; (b) CSTC for concrete contribution, $V_{\text {Rf.simplified }}$ Eq. (16) for fibres contribution and quadrilinear load-rotation relationship; and (c) CSCT for concrete contribution, $V_{R f, s i m p l i f i e d}($ Eq. (16)) for fibres contribution and load-rotation relationship through Eq. (6).
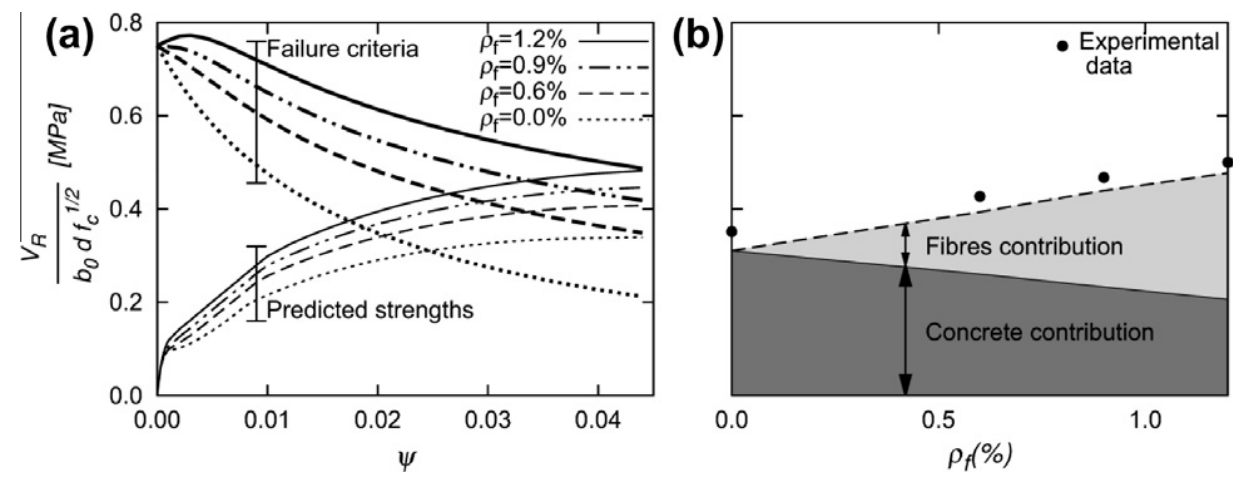

Fig. 9. Punching shear strength as a function of the fibre volume: (a) CSCT failure criteria and load-rotation relationships for elements tested by Swamy and Ali [5]; (b) experimental and predicted punching shear strengths.

designs. Using this simplified load-rotation relationship, together with Eq. (16) (average fibre bridging stress), the average ratio between measured-to-predicted punching shear strength is 1.13 with a coefficient of variation of 0.09 (Fig. 8c).

\section{Role of fibres on the punching shear strength}

A series of the elements tested by Swamy and Ali [5] were selected to gain a better understanding of the predicted effect of the steel fibre volume on the punching shear strength of slabcolumn connections. The selected test elements had identical geometrical dimensions and fibre type and the concrete compressive strength was similar for all batches. The failure criteria and the estimated load rotation relationships for the elements selected are presented in Fig. 9a. As is shown in Fig. 9b, the proposed model predicts well the increase of the punching shear strength with the increase of the fibre volume. Furthermore, an increase in the quantity of similar fibres provides for an increase in the deformational capacity. As the concrete contribution to the punching strength decreases with the increase of the slab rotation, the weight of the fibre contribution becomes more relevant to the resistance mechanism. The predicted concrete and fibres contributions to the punching shear strength for elements tested by Swamy and Ali ([5] are shown in Fig. 9b, with an excellent correlation observed between the model predictions and the test results.

\section{Code-like formulation}

For design purposes a code-like formulation is developed in accordance with the simpler approach proposed above, i.e. the load-rotation relationship estimated by Eq. (6) and average fibre bridging stress according to Eq. (16). Regarding the shear component carried by the concrete, $V_{R d, c}$, Eq. (1) has to be replaced by the failure criterion proposed by Muttoni [17], using characteristic values to reach a target lower fractile value of $5 \%$ and considering partial safety factors. This is given as

$\frac{V_{R d, c}}{b_{0} d \sqrt{f_{c}}}=\frac{2}{3 \gamma_{c}} \frac{1}{1+20 \frac{\psi d}{d_{g 0}+d_{g}}}$

where $\gamma_{c}$ is the partial safety factor of concrete and equal to 1.5 according to the European practice. The introduction of a suitable safety format and partial safety factors is discussed in Muttoni

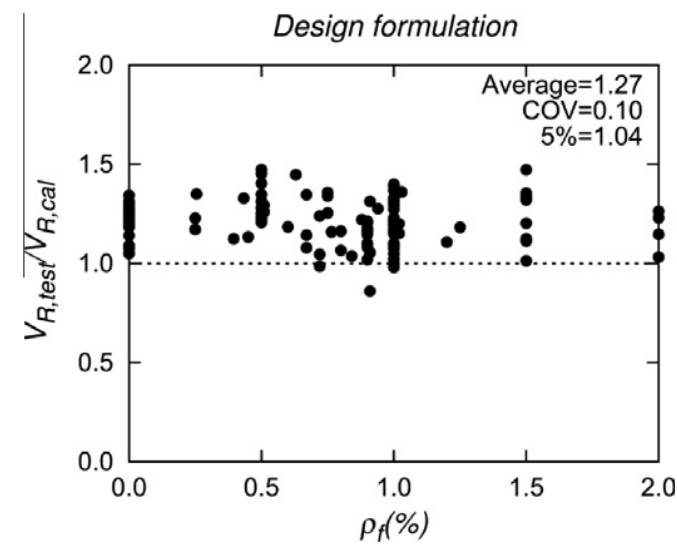

Fig. 10. Punching shear strength predictions for SFRC slabs using the design formulation proposed. 
(a) Narayanan and Darwish [6]

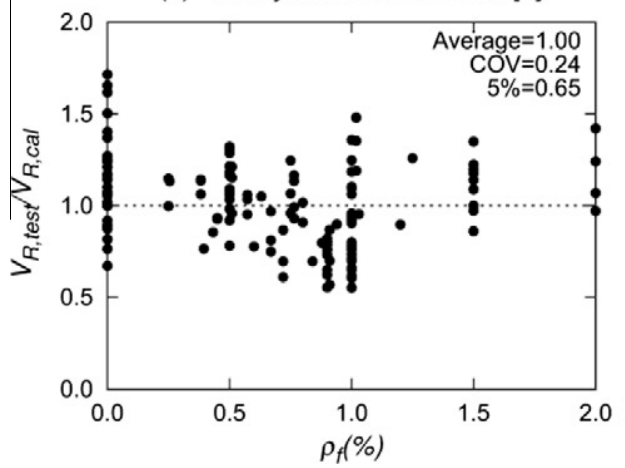

(b) Harajli et al. [8]

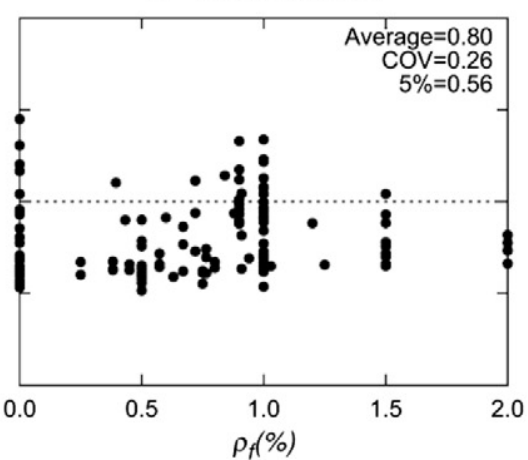

(c) Higashiyama et al. [16]

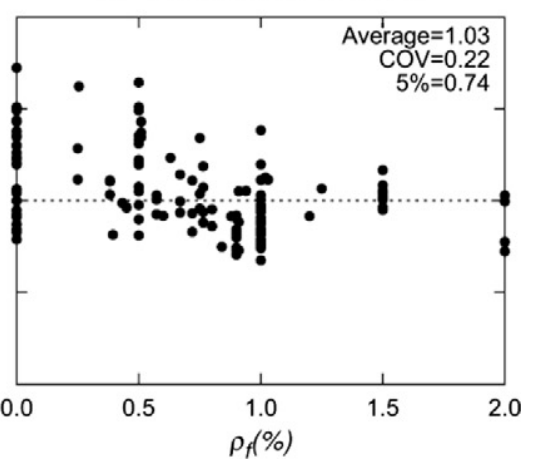

Fig. 11. Punching shear strength predictions for SFRC slabs (a) Model proposed by Narayanan and Darwish [6]; (b) Model proposed by Harajli et al. [8]; and (c) Model proposed by Higashiyama et al. [16].

and Fernández Ruiz [21]. The fibres contribution is assessed by calculating the average fibre bridging stress at the control distance from the soffit of the slab, as stated in Eq. (16).

Fig. 10 shows the ratio between the experimentally measured punching shear strength and the punching shear strength calculated through the proposed design formula for the experimental database (all safety factors were set to 1.0 for comparison to test results). The average value of the ratio between effective and predicted punching strength increases to 1.27 , with a coefficient of variation of 0.10 . A satisfactory safety level for the design formulation was assessed, being the ratio for the $5 \%$ lower fractile equal to 1.04 .

\section{Comparison to other prediction models}

The experimental data is used to assess the strength predictions according to the models proposed by Narayanan and Darwish [6], Harajli et al. [8] and Higashiyama et al. [16], and the results obtained are shown in Fig. 11. The expressions used for the comparison are detailed in Appendix B of this paper. The results of these three empirically-based models show a significant degree of scatter when compared to the available test dataset, with relatively low average test to predicted model ratios and high standard deviations. This large scatter leads to rather low values for the 5 th percentile target fractile ( 0.65 for Narayanan and Darwish, 0.56 for Harajli et al. and 0.74 for Higashiyama et al.), which in all cases are below 1.0. Moreover, the largely empirical background of these models is inconsistent with the new approaches for punching shear currently adopted in codes provisions, such as the one adopted in the Model Code 2010 [13,14], where more physical models are considered to describe behaviour.

\section{Conclusions}

This paper presents an analytical approach for assessing the punching shear strength of steel fibre reinforced concrete slab-column connections. Unlike most design formulations available in the literature, a physical-mechanical model based on the critical shear crack theory is proposed.

1. The contribution of concrete and fibres are considered coupled through the main hypothesis of the critical shear crack theory (CSCT), which establishes that the shear critical crack opening is proportional to the product of the rotation of the slab and the effective depth of the member.

2. The contribution of the concrete to the punching shear strength takes into account the main geometric and mechanical parameters and reproduces accurately the pronounced size effect.
3. For assessing the fibre contribution to the punching shear strength, a crack opening-fibre bridging stress relationship is required. According to the approach for fibre reinforced concretes adopted in most of the current design codes, calibration of material parameters needs to be done on the basis of test results. Alternatively, the Variable Engagement Model proposed by Voo and Foster can be used to assess the tensile behaviour of fibre reinforced concretes.

4. The proposed approach was compared to 140 slab-column connection tests reported in the literature. The proposed prediction model exhibits a good agreement with the test results and properly represents the influence of the fibres on the punching strength of FRC slab-column connections.

5. A simplified approach suitable for typical designs is proposed that leads to good estimates of the punching shear strength and sufficient safety.

6. A number of empirical design formulas show significant scatter when compared to test results and lead potentially to unsafe estimates of the punching shear strength.

\section{Appendix A}

See Table A1.

\section{Appendix B}

\section{B.1. Model by Narayanan and Darwish [6]}

Eq. (B.1) presents the simplified expression developed by Narayanan and Darwish [6] to estimate the ultimate punching shear strength of FCR slabs.

$$
\begin{aligned}
& \frac{V_{u}}{b_{p f} d}=\lambda_{s}\left(0.24 f_{s p f}+16 \rho+v_{b}\right) \\
& f_{s p f}=\frac{f_{c f, c u b}}{20-\sqrt{F}}+0.7+\sqrt{F} \\
& b_{p f}=b_{0,1.5 d}(1-0.55 F) \\
& \lambda_{s}=1.6-0.002 h
\end{aligned}
$$

where $\lambda_{s}$ is the size effect factor that depends on the slab depth $h$; $F=k_{b} l_{f} \rho_{f} / d_{f}$ is the fibre parameter considering; $k_{b}$ is the bond factor; $\rho_{f}$ is the fibre volume, and $l_{f}$ and $d_{f}$ are the length and diameter of fibre, respectively. The ultimate split cylinder strength of steel fibre reinforced concrete $f_{s p f}$ is calculated assuming a compressive cube strength of the fibre reinforce concrete equivalent to $f_{c} / 0.8$. The vertical fibre pull-out stress along the inclined crack $v_{b}$ is calculated as $0.41 \tau F$, where the fibre-matrix interfacial bond stress $\tau_{b}$ is assumed 
Table A1

Experimental data base and strength predictions.

\begin{tabular}{|c|c|c|c|c|c|c|c|c|c|c|}
\hline Specimen & $h(\mathrm{~mm}$ & $d(\mathrm{~mm})$ & $b_{c}^{\mathrm{a}}(\mathrm{mm})$ & $f_{c}(\mathrm{MPa})$ & $\rho(\%)$ & $\rho_{f}(\%)$ & $V_{\text {exp }}(\mathrm{kN})$ & $\frac{V_{\exp } \mathrm{b}}{V_{R, e s t 1}}$ & $\frac{V_{\text {exp }} \mathrm{c}}{V_{R, \text { est2 }}}$ & $\frac{V_{e x p}}{V_{R, d}} \mathrm{~d}$ \\
\hline \multicolumn{11}{|c|}{ Cheng and Parra-Montesinos [10] } \\
\hline S1 & 152 & 127 & 152 & 47.7 & 0.98 & 0.00 & 433 & 1.10 & 1.19 & 1.38 \\
\hline S2 & 152 & 127 & 152 & 47.7 & 0.66 & 0.00 & 379 & 1.16 & 1.22 & 1.42 \\
\hline S3/FRC & 152 & 127 & 152 & 25.4 & 0.98 & 1.00 & 386 & 1.01 & 1.09 & 1.25 \\
\hline S4/FRC & 152 & 127 & 152 & 25.4 & 0.66 & 1.00 & 389 & 1.15 & 1.20 & 1.37 \\
\hline S5/FRM & 152 & 127 & 152 & 59.3 & 0.98 & 1.50 & 530 & 1.03 & 1.12 & 1.27 \\
\hline S6/FRM & 152 & 127 & 152 & 57.9 & 0.66 & 1.50 & 444 & 1.03 & 1.03 & 1.16 \\
\hline S7/FRC & 152 & 127 & 152 & 31.0 & 0.98 & 1.50 & 522 & 1.15 & 1.23 & 1.41 \\
\hline S8/FRC & 152 & 127 & 152 & 31.0 & 0.66 & 1.50 & 472 & 1.19 & 1.20 & 1.36 \\
\hline S9/FRC & 152 & 127 & 152 & 46.1 & 0.98 & 1.50 & 530 & 0.94 & 0.93 & 1.03 \\
\hline S10/FRC & 152 & 127 & 152 & 59.1 & 0.66 & 1.50 & 503 & 1.12 & 1.12 & 1.12 \\
\hline \multicolumn{11}{|c|}{ Theodorakopoulos and Swamy [28] } \\
\hline FS-1 & 125 & 100 & 150 & 35.4 & 0.56 & 0.00 & 173.5 & 1.10 & 1.20 & 1.40 \\
\hline FS-2 & 125 & 100 & 150 & 34.0 & 0.56 & 0.50 & 225 & 1.17 & 1.23 & 1.41 \\
\hline FS-3 & 125 & 100 & 150 & 35.6 & 0.56 & 1.00 & 247.4 & 1.07 & 1.09 & 1.19 \\
\hline FS-4 & 125 & 100 & 150 & 35.7 & 0.56 & 1.00 & 224.4 & 0.97 & 0.99 & 1.08 \\
\hline FS-5 & 125 & 100 & 150 & 38.0 & 0.37 & 1.00 & 198.1 & 1.08 & 1.15 & 1.15 \\
\hline FS-6 & 125 & 100 & 150 & 35.7 & 0.37 & 1.00 & 174.5 & 0.96 & 1.02 & 1.02 \\
\hline FS-7 & 125 & 100 & 150 & 36.6 & 0.37 & 1.00 & 192.4 & 1.06 & 1.12 & 1.12 \\
\hline FS-19 & 125 & 100 & 150 & 34.5 & 0.37 & 0.00 & 136.5 & 1.12 & 1.16 & 1.35 \\
\hline FS-20 & 125 & 100 & 150 & 37.0 & 0.37 & 1.00 & 211 & 1.06 & 1.10 & 1.10 \\
\hline FS-8 & 125 & 100 & 100 & 36.7 & 0.56 & 0.00 & 150.3 & 1.06 & 1.19 & 1.38 \\
\hline FS-9 & 125 & 100 & 100 & 35.6 & 0.56 & 1.00 & 216.6 & 1.06 & 1.12 & 1.26 \\
\hline FS-10 & 125 & 100 & 200 & 36.4 & 0.56 & 0.00 & 191.4 & 1.10 & 1.17 & 1.36 \\
\hline FS-11 & 125 & 100 & 200 & 34.2 & 0.56 & 1.00 & 259.8 & 1.07 & 1.11 & 1.11 \\
\hline FS-12 & 125 & 100 & 150 & 36.1 & 0.56 & 1.00 & 217.5 & 1.10 & 1.13 & 1.28 \\
\hline FS-13 & 125 & 100 & 150 & 33.5 & 0.56 & 1.00 & 235.5 & 0.96 & 0.99 & 1.00 \\
\hline FS-14 & 125 & 100 & 150 & 35.0 & 0.56 & 1.00 & 239.5 & 1.16 & 1.22 & 1.40 \\
\hline FS-15 & 125 & 100 & 150 & 31.2 & 0.56 & 1.00 & 238 & 1.12 & 1.13 & 1.26 \\
\hline FS-16 & 125 & 100 & 150 & 27.9 & 0.56 & 1.00 & 227.8 & 1.18 & 1.27 & 1.46 \\
\hline FS-17 & 125 & 100 & 150 & 46.8 & 0.56 & 1.00 & 268.4 & 1.20 & 1.23 & 1.40 \\
\hline FS-18 & 125 & 100 & 150 & 14.2 & 0.56 & 1.00 & 166 & 1.09 & 1.20 & 1.39 \\
\hline \multicolumn{11}{|c|}{ Alexander and Simmonds [7] } \\
\hline P11F0 & 155 & 132.7 & 200 & 33.2 & 0.50 & 0.00 & 257 & 0.95 & 0.98 & 1.15 \\
\hline P11F31 & 155 & 132.7 & 200 & 35.8 & 0.50 & 0.39 & 324 & 1.04 & 1.02 & 1.18 \\
\hline P11F66 & 155 & 132.7 & 200 & 35.0 & 0.50 & 0.84 & 345 & 0.98 & 0.97 & 1.04 \\
\hline P38F0 & 155 & 105.7 & 200 & 38.1 & 0.63 & 0.00 & 264 & 1.22 & 1.27 & 1.48 \\
\hline P38F34 & 155 & 105.7 & 200 & 38.4 & 0.63 & 0.43 & 308 & 1.21 & 1.21 & 1.40 \\
\hline P38F69 & 155 & 105.7 & 200 & 38.5 & 0.63 & 0.88 & 330 & 1.12 & 1.09 & 1.23 \\
\hline \multicolumn{11}{|c|}{ De Hanai and Holanda [29] } \\
\hline L1 & 100 & 80 & 80 & 23.1 & 1.56 & 0.00 & 137.2 & 1.10 & 1.14 & 1.31 \\
\hline L2 & 100 & 80 & 80 & 24.4 & 1.56 & 1.00 & 139.6 & 0.94 & 1.02 & 1.18 \\
\hline L3 & 100 & 80 & 80 & 28.1 & 1.56 & 2.00 & 163.6 & 0.89 & 1.00 & 1.16 \\
\hline L4 & 100 & 80 & 80 & 57.0 & 1.56 & 0.00 & 192.9 & 1.06 & 1.13 & 1.31 \\
\hline L5 & 100 & 80 & 80 & 59.7 & 1.56 & 1.00 & 215.1 & 0.98 & 1.07 & 1.24 \\
\hline L6 & 100 & 80 & 80 & 52.4 & 1.56 & 2.00 & 236.2 & 0.97 & 1.08 & 1.25 \\
\hline OSC S1 & 100 & 80 & 80 & 43.7 & 1.56 & 0.00 & 176.5 & 1.08 & 1.14 & 1.32 \\
\hline L7 & 100 & 80 & 80 & 36.6 & 1.56 & 0.75 & 182.5 & 1.12 & 1.20 & 1.38 \\
\hline L8 & 100 & 80 & 80 & 46.1 & 1.56 & 1.50 & 210.9 & 1.08 & 1.19 & 1.38 \\
\hline \multicolumn{11}{|c|}{ Swamy and Ali [5] } \\
\hline S-1 & 125 & 100 & 150 & 37.8 & 0.56 & 0.00 & 197.7 & 1.13 & 1.19 & 1.38 \\
\hline $\mathrm{S}-2$ & 125 & 100 & 150 & 39.0 & 0.56 & 0.60 & 243.6 & 1.08 & 1.08 & 1.21 \\
\hline $\mathrm{S}-3$ & 125 & 100 & 150 & 37.8 & 0.56 & 0.90 & 262.9 & 1.06 & 1.08 & 1.15 \\
\hline$S-4$ & 125 & 100 & 150 & 36.9 & 0.56 & 1.20 & 281.0 & 1.05 & 1.07 & 1.09 \\
\hline S-5 & 125 & 100 & 150 & 37.8 & 0.56 & 0.90 & 267.2 & 1.17 & 1.22 & 1.22 \\
\hline S-6 & 125 & 100 & 150 & 38.0 & 0.56 & 0.90 & 239.0 & 1.05 & 1.09 & 1.09 \\
\hline S-7 & 125 & 100 & 150 & 38.9 & 0.74 & 0.00 & 221.7 & 1.19 & 1.34 & 1.56 \\
\hline S-13 & 125 & 100 & 150 & 39.3 & 0.74 & 0.90 & 236.7 & 1.09 & 1.14 & 1.31 \\
\hline S-12 & 125 & 100 & 150 & 36.8 & 0.74 & 0.90 & 249.0 & 1.00 & 1.05 & 1.05 \\
\hline S-11 & 125 & 100 & 150 & 37.1 & 0.74 & 0.90 & 262.0 & 1.11 & 1.15 & 1.22 \\
\hline $\mathrm{S}-8$ & 125 & 100 & 150 & 41.1 & 0.74 & 0.90 & 255.7 & 1.07 & 1.11 & 1.14 \\
\hline S-16 & 125 & 100 & 150 & 38.9 & 0.56 & 0.90 & 213.0 & 1.14 & 1.25 & 1.25 \\
\hline$S-10$ & 125 & 100 & 150 & 38.9 & 0.46 & 0.90 & 203.0 & 1.18 & 1.32 & 1.32 \\
\hline S-9 & 125 & 100 & 150 & 38.9 & 0.37 & 0.90 & 179.3 & 1.15 & 1.31 & 1.31 \\
\hline S-19 & 125 & 100 & 150 & 38.9 & 0.37 & 0.00 & 130.7 & 1.23 & 1.32 & 1.32 \\
\hline \multicolumn{11}{|c|}{ McHarg et al. [9] } \\
\hline NU & 150 & 109 & 225 & 30.0 & 1.12 & 0.00 & 306.0 & 1.01 & 1.07 & 1.24 \\
\hline NB & 150 & 109 & 225 & 30.0 & 2.18 & 0.00 & 349.0 & 1.08 & 1.24 & 1.44 \\
\hline FSU & 150 & 109 & 225 & 41.5 & 1.12 & 0.50 & 422.0 & 1.12 & 1.15 & 1.32 \\
\hline FSB & 150 & 109 & 225 & 41.5 & 2.18 & 0.50 & 438.0 & 1.12 & 1.22 & 1.39 \\
\hline
\end{tabular}

Suter and Moreillon [30] 
Table A1 (continued)

\begin{tabular}{|c|c|c|c|c|c|c|c|c|c|c|}
\hline Specimen & $h(\mathrm{~mm}$ & $d(\mathrm{~mm})$ & $b_{c}^{\mathrm{a}}(\mathrm{mm})$ & $f_{c}(\mathrm{MPa})$ & $\rho(\%)$ & $\rho_{f}(\%)$ & $V_{\text {exp }}(\mathrm{kN})$ & $\frac{V_{\text {exp }} \mathrm{b}}{V_{R, \text { est1 }}}$ & $\frac{V_{\text {exp }} \mathrm{c}}{V_{R, \text { est2 }}}$ & $\frac{V_{e x p}}{V_{R, d}} \mathrm{~d}$ \\
\hline B1-01 & 120 & 90 & 60 & 99.0 & 0.87 & 0.00 & 262.0 & 1.12 & 1.21 & 1.41 \\
\hline B2-01 & 120 & 90 & 60 & 103.0 & 0.87 & 0.25 & 318.0 & 1.21 & 1.28 & 1.47 \\
\hline B3-01 & 120 & 90 & 60 & 108.0 & 0.87 & 0.51 & 343.0 & 1.16 & 1.20 & 1.37 \\
\hline B4-01 & 120 & 90 & 60 & 106.0 & 0.87 & 0.76 & 337.0 & 1.05 & 1.06 & 1.20 \\
\hline B5-01 & 120 & 90 & 60 & 107.0 & 0.87 & 1.02 & 369.0 & 1.05 & 1.05 & 1.17 \\
\hline B1-05 & 120 & 92 & 60 & 99.0 & 0.55 & 0.00 & 201.0 & 1.13 & 1.17 & 1.29 \\
\hline B3-05 & 120 & 92 & 60 & 108.0 & 0.55 & 0.51 & 286.0 & 1.22 & 1.26 & 1.26 \\
\hline B5-05 & 120 & 92 & 60 & 107.0 & 0.55 & 1.02 & 327.0 & 1.13 & 1.17 & 1.17 \\
\hline B1-06 & 120 & 88 & 60 & 99.0 & 1.29 & 0.00 & 252.0 & 0.95 & 1.04 & 1.20 \\
\hline B3-06 & 120 & 88 & 60 & 108.0 & 1.29 & 0.51 & 361.0 & 1.10 & 1.18 & 1.35 \\
\hline B5-06 & 120 & 88 & 60 & 107.0 & 1.29 & 1.02 & 402.0 & 1.05 & 1.10 & 1.24 \\
\hline \multicolumn{11}{|c|}{ Nguyen-Minh et al. [31] } \\
\hline AO & 125 & 105 & 200 & 21.7 & 0.66 & 0.0 & 284.0 & 1.00 & 1.07 & 1.24 \\
\hline $\mathrm{A} 1$ & 125 & 105 & 200 & 22.3 & 0.66 & 0.4 & 330.0 & 1.04 & 1.11 & 1.28 \\
\hline $\mathrm{A} 2$ & 125 & 105 & 200 & 23.4 & 0.66 & 0.6 & 345.0 & 1.03 & 1.08 & 1.25 \\
\hline A3 & 125 & 105 & 200 & 25.3 & 0.66 & 0.8 & 397.0 & 1.10 & 1.15 & 1.32 \\
\hline B0 & 125 & 105 & 200 & 21.7 & 0.66 & 0.0 & 301.0 & 1.19 & 1.28 & 1.49 \\
\hline B1 & 125 & 105 & 200 & 22.3 & 0.66 & 0.4 & 328.0 & 1.17 & 1.22 & 1.41 \\
\hline B2 & 125 & 105 & 200 & 23.4 & 0.66 & 0.6 & 337.0 & 1.13 & 1.16 & 1.33 \\
\hline B3 & 125 & 105 & 200 & 25.3 & 0.66 & 0.8 & 347.0 & 1.08 & 1.09 & 1.25 \\
\hline $\mathrm{CO}$ & 125 & 105 & 200 & 21.7 & 0.66 & 0.0 & 264.0 & 1.15 & 1.24 & 1.44 \\
\hline $\mathrm{C} 1$ & 125 & 105 & 200 & 22.3 & 0.66 & 0.4 & 307.0 & 1.19 & 1.24 & 1.43 \\
\hline $\mathrm{C} 2$ & 125 & 105 & 200 & 23.4 & 0.66 & 0.6 & 310.0 & 1.13 & 1.15 & 1.31 \\
\hline C3 & 125 & 105 & 200 & 25.3 & 0.66 & 0.8 & 326.0 & 1.00 & 1.09 & 1.24 \\
\hline \multicolumn{11}{|c|}{ Harajli et al. [8] } \\
\hline $\mathrm{A} 1$ & 55 & 39 & 100 & 29.6 & 1.12 & 0.00 & 58.8 & 1.05 & 1.08 & 1.25 \\
\hline $\mathrm{A} 2$ & 55 & 39 & 100 & 30.0 & 1.12 & 0.45 & 63.6 & 0.98 & 1.01 & 1.16 \\
\hline A3 & 55 & 39 & 100 & 31.4 & 1.12 & 0.80 & 73.1 & 0.99 & 1.03 & 1.18 \\
\hline A4 & 55 & 39 & 100 & 24.6 & 1.12 & 1.00 & 64.7 & 1.03 & 1.09 & 1.24 \\
\hline A5 & 55 & 39 & 100 & 20.0 & 1.12 & 2.00 & 58.3 & 0.86 & 0.91 & 1.04 \\
\hline B1 & 75 & 55 & 100 & 31.4 & 1.12 & 0.00 & 91.8 & 0.94 & 1.00 & 1.13 \\
\hline B2 & 75 & 55 & 100 & 31.4 & 1.12 & 0.45 & 105.9 & 0.94 & 1.02 & 1.16 \\
\hline B3 & 75 & 55 & 100 & 31.8 & 1.12 & 0.80 & 108.4 & 0.87 & 0.94 & 1.08 \\
\hline B4 & 75 & 55 & 100 & 29.1 & 1.12 & 1.00 & 108.8 & 0.96 & 1.04 & 1.19 \\
\hline B5 & 75 & 55 & 100 & 29.2 & 1.12 & 2.00 & 134.5 & 1.00 & 1.10 & 1.27 \\
\hline \multicolumn{11}{|l|}{ Yaseen [32] } \\
\hline S11 & 60 & 44 & 100 & 35.4 & 1.61 & 0.50 & 89.5 & 1.02 & 1.09 & 1.26 \\
\hline $\mathrm{S} 12$ & 60 & 44 & 100 & 49.1 & 1.61 & 0.50 & 102.5 & 1.02 & 1.09 & 1.25 \\
\hline S13 & 60 & 44 & 100 & 55.1 & 1.61 & 0.50 & 129.5 & 1.24 & 1.31 & 1.51 \\
\hline S14 & 60 & 44 & 100 & 65.1 & 1.61 & 0.50 & 141.0 & 1.26 & 1.34 & 1.54 \\
\hline S21 & 60 & 44 & 100 & 42.2 & 1.61 & 0.00 & 93.3 & 1.13 & 1.18 & 1.36 \\
\hline S22 & 60 & 44 & 100 & 48.8 & 1.61 & 0.25 & 98.0 & 1.04 & 1.11 & 1.28 \\
\hline $\mathrm{S} 23$ & 60 & 44 & 100 & 52.4 & 1.61 & 0.75 & 125.5 & 1.15 & 1.23 & 1.40 \\
\hline $\mathrm{S} 24$ & 60 & 44 & 100 & 53.3 & 1.61 & 1.00 & 138.0 & 1.19 & 1.26 & 1.44 \\
\hline S31 & 60 & 44 & 100 & 49.2 & 1.61 & 0.50 & 98.0 & 1.06 & 1.13 & 1.30 \\
\hline S32 & 60 & 44 & 100 & 49.2 & 1.61 & 0.50 & 100.0 & 1.06 & 1.13 & 1.30 \\
\hline S33 & 60 & 44 & 100 & 52.8 & 1.61 & 0.50 & 117.5 & 1.19 & 1.27 & 1.46 \\
\hline S34 & 60 & 44 & 100 & 49.5 & 1.61 & 0.50 & 110.0 & 1.13 & 1.21 & 1.40 \\
\hline S41 & 60 & 44 & 75 & 51.1 & 1.61 & 0.50 & 88.5 & 1.02 & 1.09 & 1.25 \\
\hline S42 & 60 & 44 & 150 & 50.8 & 1.61 & 0.50 & 135.0 & 1.05 & 1.10 & 1.27 \\
\hline \multicolumn{11}{|c|}{ Narayanan and Darwish [6] } \\
\hline S1 & 60 & 45 & 100 & 43.3 & 1.84 & 0.00 & 86.5 & 1.06 & 1.12 & 1.29 \\
\hline S2 & 60 & 45 & 100 & 52.1 & 1.84 & 0.25 & 93.4 & 0.99 & 1.06 & 1.22 \\
\hline S3 & 60 & 45 & 100 & 44.7 & 1.84 & 0.50 & 102.0 & 1.07 & 1.15 & 1.32 \\
\hline S4 & 60 & 45 & 100 & 46.0 & 1.84 & 0.75 & 107.5 & 1.05 & 1.13 & 1.29 \\
\hline S5 & 60 & 45 & 100 & 53.0 & 1.84 & 1.00 & 113.6 & 0.99 & 1.05 & 1.20 \\
\hline S6 & 60 & 45 & 100 & 53.0 & 1.84 & 1.25 & 122.2 & 1.00 & 1.06 & 1.21 \\
\hline S7 & 60 & 45 & 100 & 47.0 & 1.60 & 1.00 & 92.6 & 0.87 & 0.93 & 1.06 \\
\hline S8 & 60 & 45 & 100 & 45.3 & 2.08 & 1.00 & 111.1 & 1.00 & 1.08 & 1.24 \\
\hline S9 & 60 & 45 & 100 & 43.5 & 2.30 & 1.00 & 111.3 & 1.01 & 1.09 & 1.25 \\
\hline S10 & 60 & 45 & 100 & 47.6 & 2.53 & 1.00 & 111.3 & 0.96 & 1.03 & 1.19 \\
\hline S11 & 60 & 45 & 100 & 29.8 & 1.84 & 1.00 & 82.1 & 0.90 & 0.98 & 1.13 \\
\hline S12 & 60 & 45 & 100 & 32.4 & 1.84 & 1.00 & 84.9 & 0.90 & 0.98 & 1.12 \\
\hline \multicolumn{11}{|c|}{ Higashiyama et al. [16] } \\
\hline $\mathrm{t} 100-0.67$ & 100 & 70 & 100 & 24.6 & 0.85 & 0.67 & 137.5 & 1.20 & 1.18 & 1.36 \\
\hline $\mathrm{t} 140-0.67$ & 140 & 110 & 100 & 24.6 & 0.54 & 0.67 & 210.2 & 1.07 & 1.07 & 1.14 \\
\hline $\mathrm{t} 180-0.67$ & 180 & 150 & 100 & 24.6 & 0.40 & 0.67 & 297.6 & 1.07 & 1.07 & 1.07 \\
\hline $\mathrm{t} 100-0.72$ & 100 & 65 & 100 & 42.4 & 0.91 & 0.72 & 140.8 & 1.18 & 1.18 & 1.22 \\
\hline $\mathrm{t} 140-0.72$ & 140 & 105 & 100 & 42.4 & 0.57 & 0.72 & 213.2 & 1.04 & 1.04 & 1.04 \\
\hline $\mathrm{t} 180-0.72$ & 180 & 145 & 100 & 42.4 & 0.41 & 0.72 & 290.7 & 0.99 & 0.99 & 0.99 \\
\hline $\mathrm{t} 100-0.91$ & 100 & 65 & 100 & 21.6 & 0.91 & 0.91 & 120.8 & 1.15 & 1.16 & 1.33 \\
\hline $\mathrm{t} 140-0.91$ & 140 & 105 & 100 & 21.6 & 0.57 & 0.91 & 183.1 & 0.96 & 0.95 & 1.06 \\
\hline
\end{tabular}


Table A1 (continued)

\begin{tabular}{|c|c|c|c|c|c|c|c|c|c|c|}
\hline Specimen & $h(\mathrm{~mm}$ & $d(\mathrm{~mm})$ & $b_{c}^{\mathrm{a}}(\mathrm{mm})$ & $f_{c}(\mathrm{MPa})$ & $\rho(\%)$ & $\rho_{f}(\%)$ & $V_{\exp }(\mathrm{kN})$ & $\frac{V_{\text {exp }} \mathrm{b}}{V_{R, \text { sst } 1}}$ & $\frac{V_{\text {exp }} \mathrm{c}}{V_{R, \text { est2 }}}$ & $\frac{V_{\text {exp }}}{V_{R, d}} \mathrm{~d}$ \\
\hline $\mathrm{t} 180-0.91$ & 180 & 145 & 100 & 21.6 & 0.41 & 0.91 & 231.2 & 0.83 & 0.83 & 0.85 \\
\hline $\mathrm{t} 100-0.63$ & 100 & 70 & 100 & 27.8 & 0.85 & 0.63 & 152.3 & 1.30 & 1.28 & 1.45 \\
\hline $\mathrm{t} 100-0.94$ & 100 & 70 & 100 & 31.1 & 0.85 & 0.94 & 147.9 & 1.16 & 1.16 & 1.27 \\
\hline $\mathrm{t} 100-1.03$ & 100 & 70 & 100 & 30.4 & 0.85 & 1.03 & 158.9 & 1.24 & 1.24 & 1.35 \\
\hline \multicolumn{11}{|c|}{ Wang et al. [33] } \\
\hline S1 & 120 & 100 & 200 & 17.4 & 0.98 & 0.00 & 255.0 & 1.07 & 1.13 & 1.31 \\
\hline S2 & 120 & 100 & 200 & 19.6 & 0.98 & 1.00 & 290.0 & 1.08 & 1.15 & 1.33 \\
\hline S3 & 120 & 100 & 200 & 20.2 & 0.98 & 1.50 & 315.0 & 1.12 & 1.19 & 1.37 \\
\hline S4 & 120 & 100 & 200 & 15.0 & 0.98 & 1.00 & 285.0 & 1.17 & 1.26 & 1.45 \\
\hline S5 & 120 & 100 & 200 & 14.9 & 0.98 & 1.50 & 310.0 & 1.24 & 1.33 & 1.54 \\
\hline Average & & & & & & & & 1.08 & 1.13 & 1.27 \\
\hline COV & & & & & & & & 0.09 & 0.09 & 0.10 \\
\hline $\mathbf{5 \%}$ & & & & & & & & 0.94 & 0.98 & 1.05 \\
\hline
\end{tabular}

a Length or radius of the loading pad.

b Refined model: $V_{R, c a l}$ calculated using Eq. (1) for concrete contribution and Eq. (14) for fibres contribution. A quadrilinear moment-curvature relationship for the reinforced concrete cross section was adopted.

c Simplified model: $V_{R, c a l}$ calculated using Eq. (1) for concrete contribution and Eq. (16) for fibres contribution. Eq. (6) was adopted for the moment-curvature relationship.

${ }^{\mathrm{d}}$ Design formulation: $V_{R d, c a l}$ calculated using Eq. (17) for concrete contribution and Eq. (16) for fibres contribution. Eq. (6) was considered for the load-rotation relationship.

as $4.15 \mathrm{~N} / \mathrm{mm}^{2}$. Furthermore, the authors proposed a basic critical perimeter $b_{0,1.5 d}$, initially located at distance of 1.5 times the column side from the column face.

\section{B.2. Model by Harajli et al. [8]}

Harajli et al. [8] derived an empirical equation to predict the punching shear strength of SFRC slabs. In the expression proposed the effect of the fibre type and the length to diameter ratio $l_{f} / d_{f}$ is not explicitly taken into account.

$\frac{V_{u}}{b_{0,0.5 d} d}=\left(\zeta+0.096 V_{f}\right) \sqrt{f_{c}}$

$\zeta=\min \left\{\begin{array}{l}\frac{1}{6}\left(1+\frac{2}{\beta_{c}}\right) \\ \frac{1}{12}\left(\frac{\alpha_{s} d}{b_{0,0.5 d}}+2\right) \\ \frac{1}{3}\end{array}\right.$

Where $\beta_{c}$ is the ratio of long side-short side of column; and $\alpha_{s}$ is 40 for interior columns, 30 for edge columns and 20 for corner columns.

\section{B.3. Higashiyama et al. [16]}

A design equation in accordance with the approach for shear adopted in the Japanese standard specifications for concrete structures was recently proposed by Higashiyama et al. [16]. The design equation considers the fibre pull-out strength $v_{b}$ and the perimeter of the basic critical section $b_{0}$ empirically modified by the fibre factor $F$, as proposed by Narayanan and Darwish [6].

$\frac{V_{u}}{b_{p f} d}=\beta_{d} \beta_{p} \beta_{r}\left(f_{p c d}+v_{b}\right)$

$f_{p c d}=0.20 \sqrt{f_{c}} \leqslant 1.2 \mathrm{MPa}$

$b_{p f}=b_{0,0.5 d}(1-0.32 F)$

$\beta_{d}=\sqrt[4]{\frac{1000}{d}} \leqslant 1.5$

$\beta_{p}=\sqrt[3]{100 \rho} \leqslant 1.5$

$\beta_{r}=1+\frac{1}{1+0.25 b_{0, \text { col }} / d}$

where $b_{0, c o l}$ is the perimeter of the column or loading pad and the critical section is located at a distance of $d / 2$ from the column face.

\section{Appendix C}

This appendix presents the development of the expressions for the load-rotation relationship following a similar procedure as that described in Muttoni [17]. For an isolated slab element it is assumed that the deflected shape outside the critical shear crack is conical. Thus, the curvature in tangential direction is

$\chi_{t}=-\frac{\psi}{r}$ for $r>r_{0}$

In turn, the curvatures inside the shear critical crack may be assumed constant and equal in both directions, so the deflected shape in this region is spherical:

$\chi_{r}=\chi_{t}=-\frac{\psi}{r_{0}} \quad$ for $r \leqslant r_{0}$

The internal forces described in Figs. $4 \mathrm{~b}$ and c can be calculated using the abovementioned curvatures and according to the quadrilinear moment-curvature relationship. The main parameters defining this relationship are the stiffness before and after cracking, $E I_{0}$ and $E I_{1}$ respectively; the cracking moment $m_{c r}$; the moment capacity $m_{R}$, and the tension stiffening effect $\chi_{T S}$.

Before cracking, it is assumed a linear behaviour of the concrete and the following terms are obtained neglecting the effect of the reinforcement

$$
\begin{aligned}
& E I_{0}=\frac{E_{c} h^{3}}{12} \\
& m_{c r}=\frac{f_{c t} h^{2}}{6} \\
& -\chi_{c r}=\frac{m_{c r}}{E I_{0}}=\frac{2 f_{c t}}{h E_{c}}
\end{aligned}
$$

After cracking and assuming linear-elastic behaviour of the steel reinforcement and the concrete the following expression is obtained:

$E I_{1}=\rho \beta E_{s} d^{3}\left(1-\frac{c}{d}\right)\left(1-\frac{c}{3 d}\right)$

where $c$ is the depth of the compressive zone:

$c=\rho \beta \frac{E_{s}}{E_{c}} d\left(\sqrt{1+\frac{2 E_{c}}{\rho \beta E_{s}}}-1\right)$

and $\beta$ is an efficiency factor that accounts for the orthogonal layout of the reinforcement and the reduction in the ratio between 
torsional and flexural stiffness of the slab after cracking, with a value $\beta=0.6$ proposed by Mutonni [17].

The moment capacity $m_{R}$ is calculated assuming a perfectly plastic behaviour of the reinforcement after yielding, a rectangular stress block for concrete in the compressive zone, an average tensile strength of the FRC, and neglecting the effect of the compressive reinforcement.

$$
\begin{aligned}
m_{R}= & \rho d^{2} f_{y}\left[1-\frac{\beta_{1}\left(\rho f_{y}+f_{c t 2, f} h / d\right)}{2\left(\alpha_{c c} f_{c}+f_{c t 2, f}\right)}\right] \\
& +\frac{h^{2} f_{c t 2, f}}{2}\left[1-\frac{\rho f_{y} d / h+f_{c t 2, f}}{\left(\alpha_{c c} f_{c}+f_{c t 2, f}\right)}\right]\left[1+\frac{\rho f_{y} d / h+f_{c t 2, f}}{\left(\alpha_{c c} f_{c}+f_{c t 2, f}\right)}\left(1-\beta_{1}\right)\right]
\end{aligned}
$$

The decrease in the curvature due to the tension stiffening effect, $\chi_{T S}$, is considered as a constant contribution through the following expression:

$\chi_{\mathrm{TS}}=\frac{f_{c t}}{6 \rho \beta h E_{s}}$

In turn, the curvatures $\chi_{1}$ at the beginning of the stabilized cracked regime and $\chi_{y}$ at yielding are given by:

$-\chi_{1}=\frac{m_{c r}}{E I_{1}}-\chi_{T S}$

$-\chi_{y}=\frac{m_{R}}{E I_{1}}-\chi_{T S}$

The four segments that defined the quadrilinear moment-curvature relationship correspond to four differentiated regions in the slab shown in Fig. 4. Each of these regions may be determined and delimited by the radiuses calculated substituting Eqs. (C.5), (C.10), and (C.11) into Eq. (C.1):

A first zone within the reinforcement is yielding, plastic radius $r_{y}$ :

$r_{y}=-\frac{\psi}{\chi_{y}}=\frac{\psi}{\frac{m_{R}}{E I_{1}}-\chi_{T S}} \leqslant r_{s}$

A zone in which cracking is stabilized, radius $r_{1}$ :

$r_{1}=-\frac{\psi}{\chi_{1}}=\frac{\psi}{\frac{m_{c r}}{E I_{1}}-\chi_{T S}} \leqslant r_{s}$

and a zone up to which the concrete is cracking, cracking radius $r_{c r}:$

$r_{c r}=-\frac{\psi}{\chi_{c r}}=\frac{\psi E I_{0}}{m_{c r}} \leqslant r_{s}$

For the slab portion presented in Fig. 4c, the equilibrium equation can be stated as:

$V \frac{\Delta \varphi}{2 \pi}\left(r_{q}-r_{c}\right)=-m_{r} \Delta \varphi r_{0}-\Delta \varphi \int_{r_{0}}^{r_{s}} m_{\varphi} d r$

where the radial moment $m_{r}$ at $r=r_{0}$ is calculated according to the quadrilinear moment-curvature relationship shown in Fig. 4a and using the curvature given in Eq. (C2) Thus, the load-rotation relationship can be expressed as:

$\begin{aligned} V= & \frac{2 \pi}{r_{q}-r_{c}}\left\{-m_{r} r_{0}+m_{R}\left\langle r_{y}-r_{0}\right\rangle+E I_{1} \psi\left\langle\ln \left(\frac{r_{1}}{r_{y}}\right)\right\rangle+E I_{1} \chi_{T S}\left\langle r_{1}-r_{y}\right\rangle\right. \\ & \left.+m_{c r}\left\langle r_{c r}-r_{1}\right\rangle+E I_{0} \psi\left\langle\ln \left(\frac{r_{s}}{r_{c r}}\right)\right\rangle\right\}\end{aligned}$

\section{Appendix D}

\begin{tabular}{|c|c|}
\hline$A_{p}$ & $\begin{array}{l}\text { horizontally projected area of the punching shear } \\
\text { failure surface }\end{array}$ \\
\hline$E_{c}$ & modulus of elasticity of concrete \\
\hline$E_{s}$ & modulus of elasticity of reinforcement \\
\hline$E I_{0}$ & flexural stiffness before cracking \\
\hline$E I_{1}$ & tangential flexural stiffness after cracking \\
\hline$F$ & fibre parameter $\left(k_{b} l_{f} \rho_{f} / d_{f}\right)$ \\
\hline$K_{f}$ & $\begin{array}{l}\text { global orientation factor for the Variable Engagement } \\
\text { Model }\end{array}$ \\
\hline$V$ & shear force \\
\hline$V_{\text {flex }}$ & shear force associated with flexural capacity of the slab \\
\hline$V_{R}$ & punching shear strength \\
\hline$V_{R d}$ & design punching shear strength \\
\hline$V_{R, c}$ & concrete contribution to punching shear strength \\
\hline$V_{R, \text { calc }}$ & calculated punching shear strength \\
\hline$V_{R d, c}$ & $\begin{array}{l}\text { design concrete contribution to punching shear } \\
\text { strength }\end{array}$ \\
\hline$V_{R, f}$ & fibre contribution to punching shear strength \\
\hline$V_{R, \text { test }}$ & measured punching shear strength \\
\hline$b_{0}$ & perimeter of the critical section \\
\hline$b_{0, \mathrm{col}}$ & perimeter of the column \\
\hline$b_{c}$ & Length or radius of the loading pad or column \\
\hline$b_{p f}$ & $\begin{array}{l}\text { modified perimeter of the critical section in fibre } \\
\text { reinforced concrete slabs }\end{array}$ \\
\hline$c$ & $\begin{array}{l}\text { distance from extreme compression fibre to neutral } \\
\text { axis }\end{array}$ \\
\hline$d$ & effective depth \\
\hline$d_{f}$ & diameter of a fibre \\
\hline$d_{g}$ & maximum diameter of the aggregate \\
\hline$d_{\mathrm{g} 0}$ & reference aggregate size \\
\hline$f_{c}$ & $\begin{array}{l}\text { average compressive strength of concrete (measured } \\
\text { in cylinder) }\end{array}$ \\
\hline$f_{c t, f}$ & tensile stress in fibre reinforced concrete \\
\hline$f_{s p f}$ & $\begin{array}{l}\text { ultimate split cylinder strength of steel fibre reinforced } \\
\text { concrete }\end{array}$ \\
\hline$f_{y}$ & yield strength of reinforcement \\
\hline$h$ & depth of the slab \\
\hline$h_{c}$ & control distance from the soffit of the slab \\
\hline$k_{b}$ & bond coefficient \\
\hline$l_{f}$ & length of a fibre \\
\hline$m_{c r}$ & cracking moment per unit width \\
\hline$m_{r}$ & radial moment per unit width \\
\hline$m_{t}$ & tangential moment per unit width \\
\hline$m_{R}$ & nominal moment capacity per unit width \\
\hline$r$ & radius \\
\hline$r_{0}$ & radius of the critical shear crack \\
\hline$r_{1}$ & radius of the zone in which cracking is stabilized \\
\hline$r_{c}$ & column radius \\
\hline$r_{c r}$ & radius of cracked zone \\
\hline$r_{q}$ & radius of load introduction at the perimeter \\
\hline$r_{s}$ & radius of isolated slab element \\
\hline$r_{y}$ & radius of yielded zone \\
\hline$x_{p l}$ & $\begin{array}{l}\text { depth of the equivalent rectangular compressive stress } \\
\text { block }\end{array}$ \\
\hline$w$ & critical shear crack opening \\
\hline$\Delta \varphi$ & angle of a slab sector \\
\hline$\alpha_{c c}$ & $\begin{array}{l}\text { factor that accounts for long term effects on the } \\
\text { compressive strength and unfavourable effects from } \\
\text { the way load is applied }\end{array}$ \\
\hline
\end{tabular}

The following symbols are used in the paper:

(continued on next page)

where the operator $\langle x\rangle$ is $x$ for $x>0$ and 0 for $x \leqslant 0$. 
fibre engagement parameter for Variable Engagement Model

$\alpha_{f}$

$\alpha_{s}$ fibre aspect ratio $l_{f} / d_{f}$

constant related to the column location in the structure

$\beta$ efficiency factor of bending reinforcement for stiffness calculation

$\beta_{1}$ factor relating depth of equivalent rectangular compressive stress block to neutral axis depth

$\beta_{c}$ ratio of long side-short side of column coefficient relating total rotation and critical crack width opening

\section{size effect factor}

distance (vertical) of a point with respect to the soffit of the slab

vertical fibre pull-out stress

reinforcement ratio

fibre reinforcement ratio (in volume)

fibre bridging stress

curvature in stabilized cracking

curvature at cracking

curvature in radial direction

curvature in tangential direction

yielding curvature

decrease in curvature due to tension stiffening rotation of slab outside the column region partial safety factor for concrete bond strength

\section{References}

[1] Muttoni A et al. Security of parking garages (in French: Sécurité structurale des parkings couverts). Documentation D 0226 SIA. Zürich (Switzerland):Société Suisse des ingénieurs et des architectes; 2008.

[2] Schousboe I. Bailey's crossroads collapse reviewed. J Eng Mech Div 1976;102(CO2):365-78.

[3] Kaminetzky D. Design and construction failures, lessons from forensic investigations. New York: McGraw-Hill; 1991.

[4] King S, Delatte NJ. Collapse of 2000 commonwealth avenue: punching shear case study. J Perf Constr Facil 2004;18(1):54-61.

[5] Swamy RN, Ali SAR. Punching shear behavior of reinforced slab-column connections made with steel fiber concrete. ACI Struct J 1982;79(6):392-406.

[6] Narayanan R, Darwish IYS. Punching shear tests on steel-fibre-reinforced micro-concrete slabs. Mag Concrete Res 1987;39(138):42-50.

[7] Alexander SDB, Simmonds SH. Punching shear tests of concrete slab-column joints containing fiber reinforcement. ACI Struct J 1992;89(4):425-32.

[8] Harajli $\mathrm{MH}$, Maalouf $\mathrm{D}$, Khatib $\mathrm{H}$. Effect of fibers on the punching shear strength of slab-column connections. Cement Concrete Compos 1995;17(2):161-70.

[9] McHarg PJ, Cook WD, Mitchell D, Yoon YS. Benefits of concentrated slab reinforcement and steel fibers on performance of slab-column connections. ACI Struct J 2000;97(2):225-34.

[10] Cheng MY, Parra-Montesinos GJ. Evaluation of steel fiber reinforcement for punching shear resistance in slab-column connections - Part I: Monotonically increased load. ACI Struct J 2010;107(1):101-9.

[11] ACI Committee 318. Building code requirements for structural concrete (ACl 318-011) and commentary (ACI 318R-11). Farmington Hills (MI): American Concrete Institute; 2011.

[12] JSCE. Standard specifications for concrete structures-2007, Design. Tokyo (Japan): Japan Society of Civil Engineers; 2007.

[13] Fédération Internationale du Béton (FIB). Model Code 2010 - first complete draft, vol. 1, Fédération Internationale du Béton, Bulletin 55. Lausanne (Switzerland): 2010

[14] Fédération Internationale du Béton (FIB). Model Code 2010 - first complete draft, vol. 2, Fédération Internationale du Béton, Bulletin 55. Lausanne (Switzerland): 2010.

[15] Choi K, Reda Taha M, Park H, Maji A. Punching shear strength of interior concrete slab-column connections reinforced with steel fibers. Cement Concrete Compos 2007;29(5):409-20.

[16] Higashiyama H, Ota A, Mizukoshi M. Design equation for punching capacity of SFRC slabs. Int J Concr Struct Mater 2011;5(1):35-42.

[17] Muttoni A. Punching shear strength of reinforced concrete slabs without transverse reinforcement. ACI Struct J 2008;105(4):440-50.

[18] Fernández Ruiz M, Muttoni A. Applications of critical shear crack theory to punching of reinforced concrete slabs with transverse reinforcement. AC Struct J 2009;106(4):485-94.

[19] Muttoni A, Schwartz J. Behaviour of beams and punching in slabs without shear reinforcement. In: IABSE colloquium. Zurich (Switzerland); 1991. p. 703-8.

[20] SIA. Swiss society of engineers and arquitects. SIA 262. Code 262 for concrete structures. Zürich (Switzerland) SIA; 2003.

21] Muttoni A, Fernandez M. MC2010: the critical shear crack theory as a mechanical model for punching shear design and its application to code provisions. In: FIB Bulletin 57: shear and punching shear in RC and FRC elements. Lausanne (Switzerland); 2010. p. 31-60.

[22] Aveston J, Kelly A. Theory of multiple fracture fibrous composites. J Mater Sci 1973;8(3):352-62.

[23] Lim TY, Paramasivam P, Lee SL. Analytical model for tensile behaviour of steelfibre concrete. ACI Mater J 1987;84(4):286-98.

[24] Li VC, Stang H, Krenchel H. Micromechanics of crack bridging in fiberreinforced concrete. Mater Struct 1993;26(8):486-94.

[25] Voo JYL, Foster SJ. Tensile fracture of fibre reinforced concrete: variable engagement model. In: 6th Rilem symposium of fibre reinforced, concrete (FRC). Varenna (Italy); 2004. p. 875-84.

[26] Voo JYL, Foster SJ. Analysis and Design of RPC Girders. Reactive Powder Concrete: Lambert Academic Publishing; 2009.

[27] Foster SJ. Design of FRC beams for shear using the VEM and the draft model code approach. In: FIB bulletin 57: shear and punching shear in RC and FRC elements. Lausanne (Switzerland); 2010. p. 195-210.

[28] Theodorakopoulos DD, Swamy N. Contribution of steel fibers to the strength characteristics of lightweight concrete slab-column connections failing in punching shear. ACI Struct J 1993;90(4):342-55.

[29] De Hanai JB, Holanda KMA. Similarities between punching and shear strength of steel fiber reinforced concrete (SFRC) slabs and beams. IBRACON 2008;1(1):1-16.

[30] Suter R, Moreillon L. Punching shear strength of high performance fiber reinforced concrete slabs. In: 3rd FIB international congress, Washington (USA); 2010

[31] Nguyen-Minh L, Rovnak M, Tran-Quoc T. Punching shear capacity of interior SFRC slab-column connections. J Struct Eng ASCE 2011. doi:10.1061(ASCE)ST.1943-541x.0000497.

[32] Yaseen A. Punching shear strength of steel fiber high strength reinforced concrete slabs. Master Thesis. Erbil (Iraq): College of Engineering University of Salahaddin; 2006. p. 107

[33] Wang X, Tian W, Huang Z, Zhou M, Zhao X. Analysis on punching shear behavior of the raft slab reinforced with steel fibers. Adv Concr Struct 2009;400:335-40. 